\title{
Acinetobacter Baumannii Multirresistente y su Relación con la Producción de Biopelículas
}

\author{
Multidrug-resistant Acinetobacter Baumannii and its Relationship with Biofilm Production
}

\author{
Lisset Bejarano Gonzales', Zulema Bustamante Garcia ${ }^{2}$, Neil Gamarra Gonzales ${ }^{3}$ Lucia Gallego Andres ${ }^{4}$, Magali
} Espinoza Antezana ${ }^{5}$, Fatima Funes Espinoza ${ }^{6}$, Andrea Goitia Funes ${ }^{7}$.

\section{Resumen}

\begin{abstract}
Acinetobacter baumannii es la bacteria Gram negativa asociada a infecciones intrahospitalarias por su gran facilidad de supervivencia en condiciones adversas y el desarrollo de multirresistencia a diversos antimicrobianos. Durante años se han registrado brotes hospitalarios en diferentes países asociados a esta bacteria, lo que aumentó el interés de estudio de las biopelículas y los genes involucrados en su producción, debido a que se demostró una asociación a la resistencia antibiótica.Objetivos: Establecer relacion entre la multirresistencis a los diferentes antibioticos y la formacion de biopeliculas en aislamientos de Acinetobacter baumannii. Métodos: Se estudió cepas de Acinetobacter baumannii utilizando reacción en cadena de la polimerasa (PCR) en tiempo real para la detección de genes bap, csuE, ompA, oxa-51 de 191 muestras, de igual manera se realizó la cuantificación de la biopelícula formada siguiendo la técnica descrita por Badmasti y Azizi. Resultados: Se realizó este estudio sobre 191 cepas de Acinetobacter baumannii provenientes de dos centros hospitalarios para la identificación de genes asociados a las biopelículas y posterior cuantificación de acuerdo a la técnica descrita por Badmasti y Azizi. Demostrando una asociación entre las biopelículas y la resistencia bacteriana de Acinetobacter baumannii. Conclusiones: Los resultados demostraron una asociación positiva entre la cantidad de biopelícula formada y la resistencia antibiótica, bacterias formadoras fuertes de biopelículas presentan mayor resistencia a los carbapenems. En cuanto a los genes, el gen ompA demostró una asociación con la cantidad de biofilm producido, bap y csuE son genes involucrados en el primer paso de formación de biofilm, pero no se asocian con la cantidad formada por la bacteria.
\end{abstract}

Palabras clave: Acinetobacter baumannii, carbapenémicos, farmacorresistencia microbiana, brotes de enfermedades, biopelículas

\section{Abstract}

Acinetobacter baumannii is the Gram-negative bacterium associated with hospital infections due to its great ease of survival in adverse conditions and the development of multi-resistance to various antimicrobials.

For years, hospital outbreaks have been registered in different countries associated with this bacterium, which increased the interest in studying biofilms and the genes involved in their production, since an association with antibiotic resistance was demonstrated.

Objectives: To establish a relationship between multiresistance to different antibiotics and biofilm formation in Acinetobacter baumannii isolates. Methods: acinetobacter baumannii strains were studied using real-time polymerase chain reaction (PCR) for the detection of bap, csuE, ompA, oxa-51 genes from 191 samples, in addition to the quantification of the biofilm formed following the technique described by Badmasti and Azizi. Results: this study was carried out on 191 Acinetobacter baumannii strains from two hospital centers for the identification of genes associated with biofilms and subsequent quantification according to the technique described by Badmasti and Azizi. Demonstrating an association between biofilms and Acinetobacter baumannii bacterial resistance. Conclusions: the results demonstrated a positive association between the amount of biofilm formed and antibiotic resistance. Strong biofilm-forming bacteria show greater resistance to carbapenems. Regarding the genes, the ompA gene showed an association with the amount of biofilm produced, bap and csuE are genes involved in the first step of biofilm formation, but they are not associated with the amount formed by the bacteria

Keywords: Acinetobacter baumannii, carbapenems, drug resistance, microbial, disease outbreaks, biofilms.

$\mathrm{E}$ 1 Acinetobacter baumannii es considerado un patógeno nosocomial emergente, causante de infecciones en pacientes hospitalizados sometidos a catéteres, suturas, ventiladores, humidificadores, máquinas de diálisis y otros

${ }^{1}$ Microbiologa Seguro Social Universitario, Cochabamba, Bolivia.

https://orcid.org/0000-0002-5513-6795. ${ }^{2}$ Docente Facultad de Cs. Farmaceuticas y Bioquimicas. https://orcid.org/0000-0002-3403-5944. ${ }^{3}$ Facultad de Cs. Farmaceuticas y Bioquimicas. https://orcid.org/0000-0002-4159-9916. ${ }^{4}$ Departamento de Inmunología Microbiología y Parasitología, Facultad de Medicina y Odontología, Universidad del País Vasco, España. https//orcid.org/0000-0003-2885-7789. ${ }^{5}$ Microbiologa Hospital Clinico Viedma. https://orcid.org/0000-0003-0422-4418. ${ }^{6}$ Docente Facultad de Cs. Farmaceuticas y Bioquimicas. https://orcid.org/0000-0002-3403-5944. ${ }^{7}$ Facultad de Cs. Farmaceuticas y Bioquimicas. https://orcid.org/0000-0002-6611-5981.

${ }^{\star}$ Correspondencia a: Lisset Bejarano Gonzales

Correo electrónico: liss12.bg@gmail.com

Recibido el 30 de abril de 2021. Aceptado el 12 de julio de 2021. equipos $^{1,2,3}$.

La patogenicidad de Acinetobacter baumannii se debe a dos características importantes, supervivencia por tiempos prolongados en condiciones adversas y facilidad de adquirir multirresistencia a los antibióticos. Esta bacteria ha sido causante de brotes hospitalarios en diferentes países, en Estados Unidos el 2003 con el regreso de militares de zonas como Irán y Afganistán se aislaron cepas de A. baumannii multidrogo y pandrogo resistentes ${ }^{1,3}$.

Datos epidemiológicos demostraron rápidos cambios de sensibilidad a resistente sobre carbapenémicos considerados el tratamiento ideal aumentando la estadía hospitalaria y los costos. Acinetobacter baumannii está asociada a la unidad de terapia intensiva por el uso de dispositivos médicos sobre los 


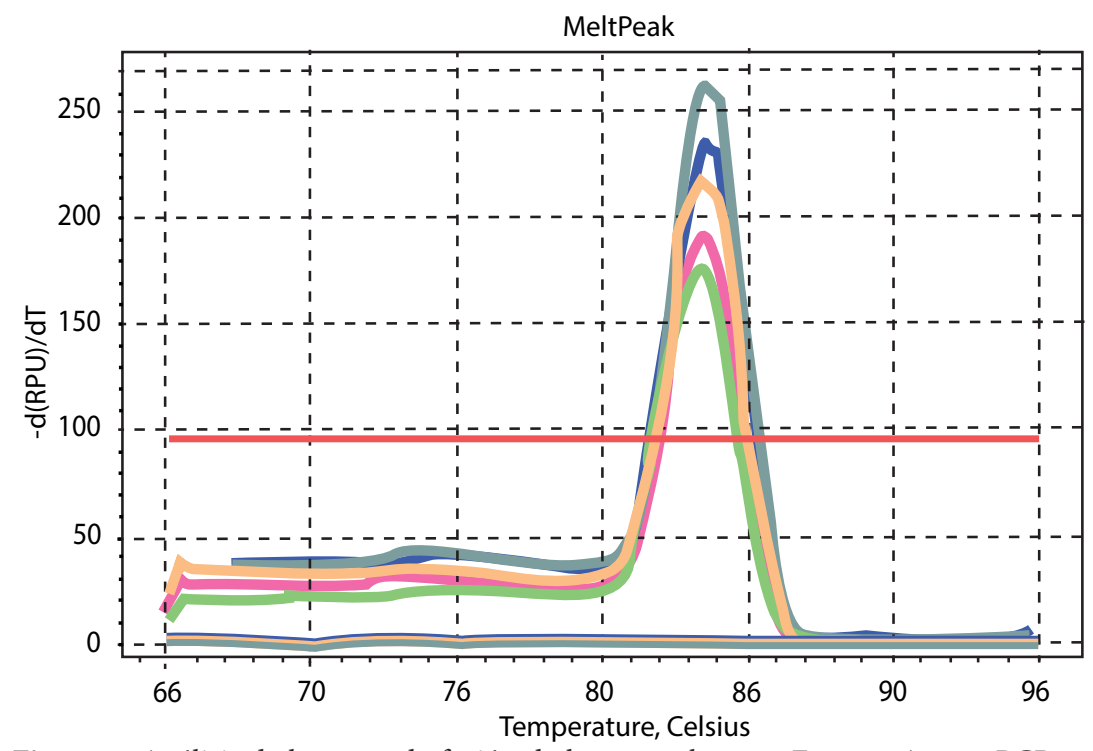

Figura 1: Análisis de la curva de fusión de los genes bap, csuE y ompA para PCR en tiempo real.

cuales se desarrollan biopelículas bacterianas ${ }^{1,4}$.

La biopelícula es una comunidad de bacterias asociadas irreversiblemente, protegidas por una capa de exopolisacáridos que permite adherirse a una superficie inerte o un tejido. Una biopelícula se establece como una estrategia de supervivencia bacteriana, un mecanismo de protección frente a fluctuaciones medioambientales ${ }^{5,6}$. De igual manera, Luo et $\mathrm{al}^{5}$ lo describe como un nido con constante intercambio de material genético responsable de nuevos genes asociados a la resistencia antimicrobiana ${ }^{5}$.

La biopelícula no está restringida a una sola especie bacteriana, por el contrario, varias especies constituyen una biopelícula, de igual manera se asocia a infecciones crónicas difíciles de eliminar en muchos casos provocando infecciones recurrentes ${ }^{6}$.

Acinetobacter baumannii ha demostrado ser un formador de biopelícula, esta bacteria tiene la facilidad de adherirse a dispositivos médicos y sobrevivir por tiempos prolongados frente a cambios de $\mathrm{pH}$, temperatura y humedad ${ }^{7}$. Esta comunidad bacteriana facilita el intercambio de nutrientes y eliminación de desechos, permite soportar altas concentraciones de antibióticos por penetración lenta e incompleta, causas metabólicas que interfieren la acción de medicamentos (anaerobiosis, $\mathrm{pH}$, etc.) e intercambio genético que potencia algunos mecanismos de resistencia ${ }^{7,8}$.

En nuestro país no existen estudios sobre biopelículas y los genes implicados en su producción, los estudios enfocados hasta la fecha se realizaron sobre otras bacterias como Staphylococcus aureus, Escherichia coli y Pseudomona aeruginosa ${ }^{7,8}$. A partir de estas investigaciones se identificaron genes ompA, csuE y bap que juegan un papel en la formación de biopelículas, es importante el estudio de estos genes para describir mecanismos que permitan bloquear la producción de biopelícula para mejorar la acción del antimicrobiano ${ }^{7}$.

El objetivo principal del estudio fue cuantificar la cantidad de biopelícula producido y asociarlo a genes ompA, csuE y
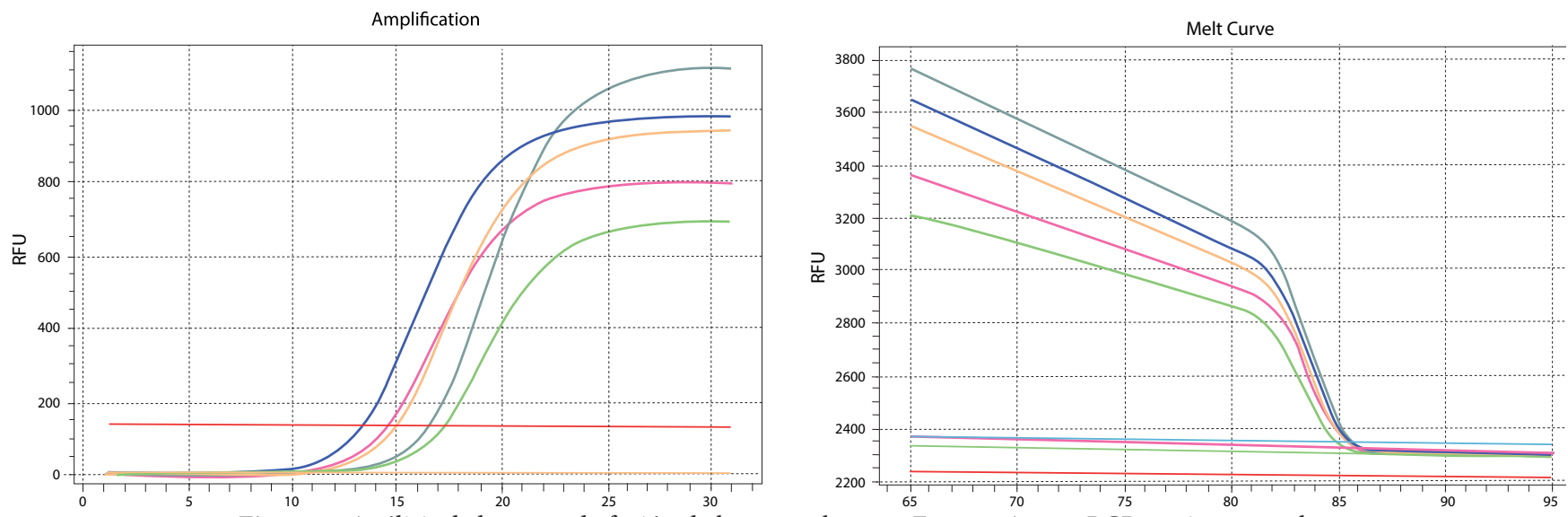

Figura 1: Análisis de la curva de fusión de los genes bap, csuE y ompA para PCR en tiempo real. 

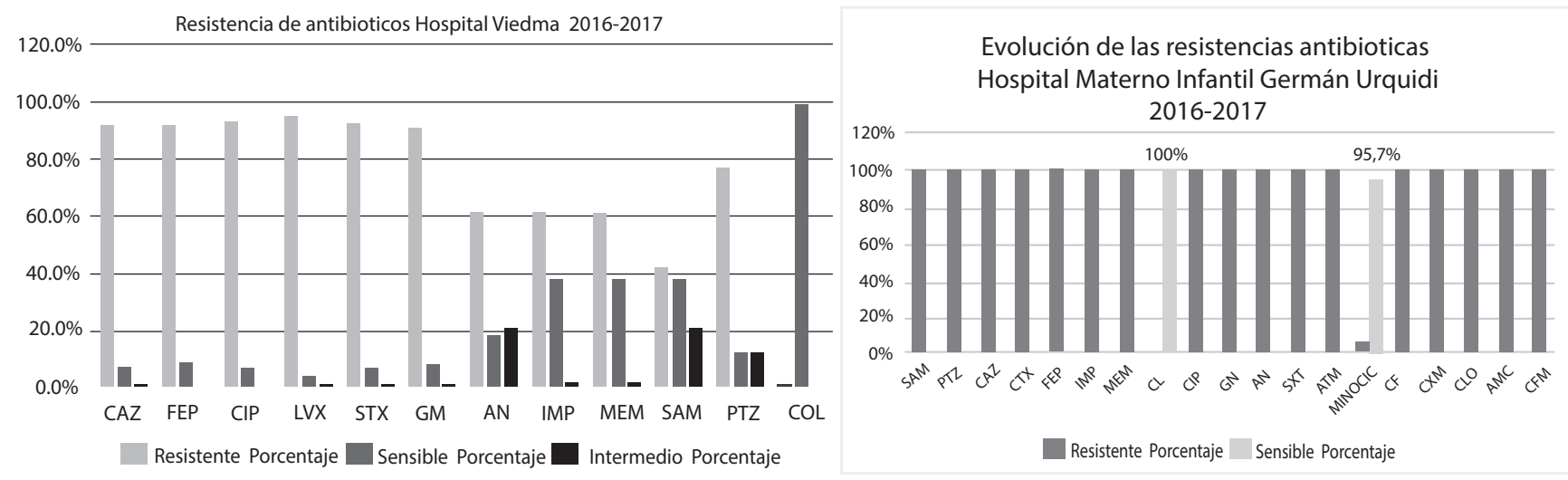

Figura 2: Perfil de resistencia a los antibióticos. A) Hospital Clínico Viedma. B) hospital Materno Infantil Germán Urquidi.

bap, identificar el gen asociado a una mayor producción de biopelícula, por último, relacionar la cantidad de biopelícula formada con la resistencia a los carbapenems 9,10,11,12.

\section{Material y métodos}

Se analizaron todas las cepas de Acinetobacter baumannii aisladas de dos centros hospitalarios de Cochabamba, Hospital Clínico Viedma (168) y Hospital Materno Infantil Germán Urquidi(HMIU) (23), durante el periodo 2016 - 2017.

Se obtuvo un total de 191 aislamientos de heridas de diferentes sitios anatómicos, hemocultivos, sonda Foley, catéteres, orina, aspirado bronquial, sonda endotraqueal y líquidos biológicos. Se realizó la identificación de Acinetobacter baumannii identificadas por PCR en tiempo real por detección de bla oxa-51, excluyendo aquellos aislamientos de que no presentaran el gen considerado un marcador de especie.

\section{Determinación de la susceptibilidad antibiótica}

Realizado en el laboratorio de Bacteriología del Hospital Clínico Viedma utilizando el método de difusión en disco de Kirby-Bauer, bajo criterios establecidos por National Committee for Clinical Laboratory Standards (CLSI), se probaron los siguientes antibióticos: Imipenem y Meropenem

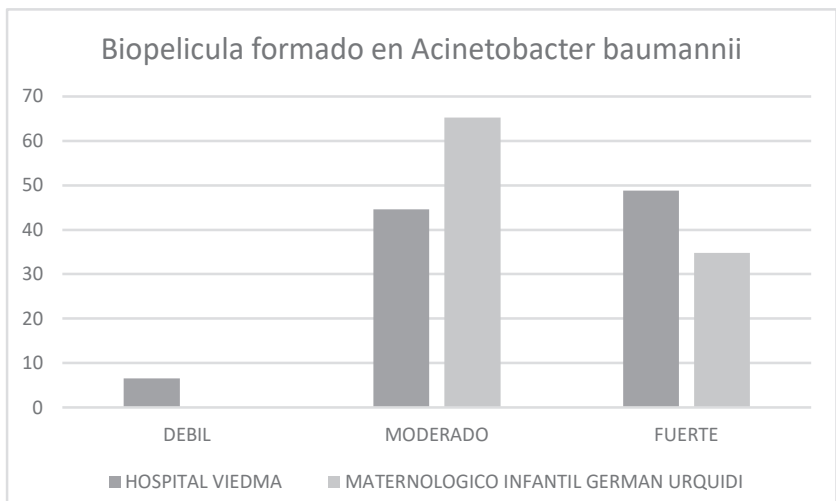

Figura 3: Clasificación del biofilm formado en A. baumannii para ambos centros hospitalarios de Cochabamba.
(10 ug), Ciprofloxacina (5 ug), Cefotaxima, Ceftazidima y Cefepime (30 ug), Gentamicina y Amikacina (30 ug), Trimetropin/sulfametoxazol (25 ug), Ampicilina sulbactam (10/10 ug), Piperacilina tazobactam (100/10 ug), Aztreonam (30 ug), Minociclina (30 ug), Levofloxacina(5ug).

Todos los antibióticos fueron sometidos a control de calidad interno de discos de sensibilidad a patógenos descritos en el manual M-100 S-10 que regula los puntos de corte de cada sensidisco estudiado, de igual manera el manual M-100 S-10 regula la interpretación de los resultados en sensible, intermedio o resistente de acuerdo a los rangos establecidos por la CLSI.

La susceptibilidad antibiótica se analizó por la técnica de Kirby-Bauer, se observó una alta resistencia en las 23 cepas provenientes del HMIU con un $100 \%$ de resistencia a Imipenem y Meropenem, Cefalosporinas, Monobactams, Quinolonas, Amikacina, Gentamicina y Sulfamidas. Para el Hospital Viedma de 168 aislamientos estudiados se encontró resistencia del $91,7 \%$ para ceftazidima y Cefepime, 93,4\% sulfonamidas. Gentamicina 91\%, piperacilina tazobactam $77,1 \%$, amikacina $61,4 \%$, Imipenem $61 \%$ y meropenem $61,3 \%$. El resultado más bajo se determinó para colistina $0,6 \%$ (Figura 2).

\section{Extracción de ADN}

Se realizó el método de hervido o boiling, a partir de

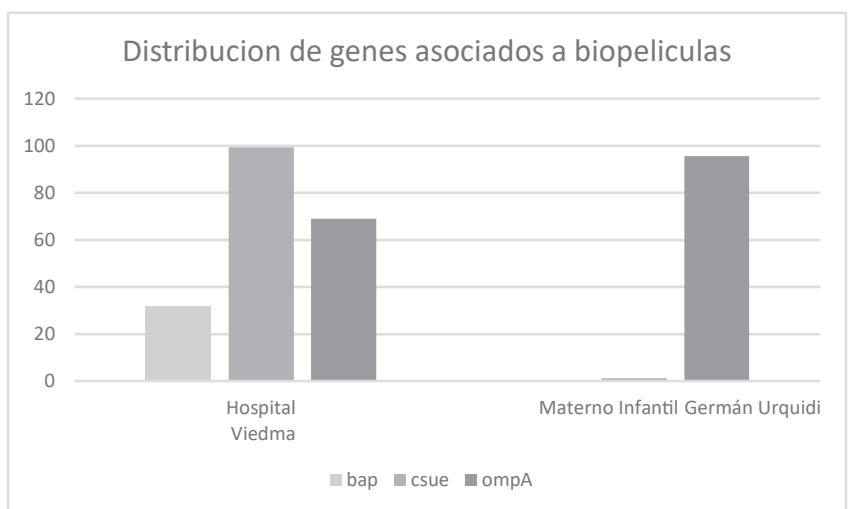

Figura 4: Detección de genes asociados a biopelículas para ambos centros hospitalarios.

Gac Med Bol 2021; 44(2):148-153 • julio - diciembre 2021 M 


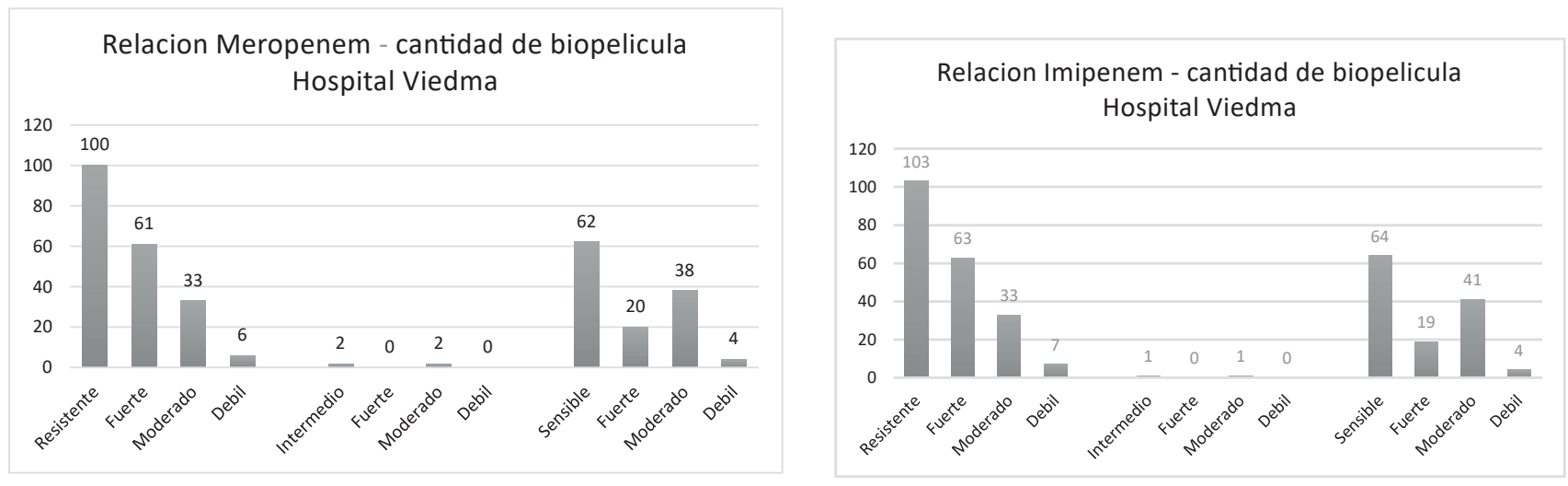

Figura 5: Relación Imipenem y Meropenem con la cantidad de biopelícula formada.

cultivos bacterianos en medio Muller Hinton se tomó una asada de colonias de la bacteria, se suspenden en agua calidad biología molecular, posteriormente se somete a $100^{\circ} \mathrm{C}$ por 15 min, centrifugar a $12000 \mathrm{rpm}$, separar el sobrenadante donde se encuentra ADN.

\section{Identificación génica de Acinetobacter baumannii}

La identificación de Acinetobacter baumannii por métodos moleculares se realizó por PCR (reacción en cadena de la polimerasa) en tiempo real se detectó bla oxa-51 denominado gen único o intrínseco identificado solo en esta bacteria a nivel del cromosoma.

Para detectar oxa-51 se llevó a cabo las siguientes condiciones: 1 ciclo inicial de $94^{\circ} \mathrm{C} 4$ min, seguidos de 30 ciclos de $94^{\circ} \mathrm{C} 30 \mathrm{~s}, 56^{\circ} \mathrm{C} 30 \mathrm{~s}, 72^{\circ} \mathrm{C} 45 \mathrm{~s}$, un ciclo final $72^{\circ} \mathrm{C} 45 \mathrm{~s}$ y una curva de melting $65^{\circ} \mathrm{C} 0,05$ s y $95^{\circ} \mathrm{C} 0,05$ s. Se utilizó el primer descrito en Tabla 1.

Detección de genes implicados en la formación de biofilm De acuerdo al método descrito por Badmasti y Azizi. Se realizó la identificación de bap, csuE y ompA en aislamiento de A. baumannii por PCR en tiempo real, los resultados obtenidos se observan en las curvas de fusión (Figura 1). Para el gen bap se utilizó los cebadores descrito por Badmasti et $\mathrm{al}^{13}$ que se indica en la Tabla 1, con las siguientes condiciones: un ciclo inicial de $94^{\circ} \mathrm{C}$ por $4 \mathrm{~min}$, seguidos de 30 ciclos de $94^{\circ} \mathrm{C}$ por $30 \mathrm{~s}$, a $55^{\circ} \mathrm{C}$ por $30 \mathrm{~s}$, a $72^{\circ} \mathrm{C}$ por $60 \mathrm{~s}$, un ciclo final $72^{\circ} \mathrm{C}$ por
60 s y una curva de melting $65^{\circ} \mathrm{C}$ por 0,05 s y $95^{\circ} \mathrm{C}$ por 0,05 s.

Para el gen csuE se utilizó el cebador indicado en la tabla 1 , de acuerdo a Azizi et al ${ }^{14}$ para un amplificado de $168 \mathrm{pb}$, con las siguientes condiciones: un ciclo inicial de $94^{\circ} \mathrm{C}$ por $4 \mathrm{~min}$, seguidos de 30 ciclos de $94^{\circ} \mathrm{C}$ por 30 s, a $59^{\circ} \mathrm{C}$ por 30 s, a $72^{\circ} \mathrm{C}$ por 60 s, un ciclo final $72^{\circ} \mathrm{C} 60$ s y una curva de melting $65^{\circ} \mathrm{C}$ por $0,05 \mathrm{~s}$ y $95^{\circ} \mathrm{C}$ por 0,05 s.

Para el gen ompA se utilizó el cebador descrito por Smani et al ${ }^{10}$ que se indica en la Tabla 1, con las siguientes condiciones: 1 ciclo inicial de $94^{\circ} \mathrm{C} 4 \mathrm{~min}$, seguidos de 30 ciclos de $94^{\circ} \mathrm{C}$ por 30 s, a $56^{\circ} \mathrm{C}$ por 30 s, a $72^{\circ} \mathrm{C}$ por 60 s, un ciclo final $72^{\circ} \mathrm{C}$ por 60 s y una curva de melting $65^{\circ} \mathrm{C}$ por $0,05 \mathrm{~s}$ y $95^{\circ} \mathrm{C}$ por 0.05 s.

\section{Cuantificación de biofilm}

Se disuelve una asada de colonia de A. baumannii en LB Broth con $0,25 \%$ por 24 horas, se realiza una dilución 1:50 en un nuevo medio LB Broth, depositar 200 ul de la dilución en pocillos de Elisa estériles e incubar por 24 horas, posteriormente desechar el sobrenadante y realizar 3 lavados con PBS, depositar 200 ul de cristal violeta $1 \%$ para teñir el biopelículas formado por 25 minutos, lavar 3 veces con PBS, resuspender con $200 \mathrm{ul}$ de alcohol acetona (80:20) el cristal violeta fijada al biopelículas y leer al $630 \mathrm{~nm}$ (Figura 4).

Los resultados de densidad obtenidos se clasificaron en no formadores $(\mathrm{DO} \leq \mathrm{Doc})$, débiles (Doc $<\mathrm{DO} \leq 2 \mathrm{Doc}$ ), moderados $(2 \mathrm{Doc}<\mathrm{DO}<4 \mathrm{DOc})$ y fuertes $(>4 \mathrm{DOc})$.

Tabla 1: Secuencias de cebadores utilizados para la identificación de A. baumannii y genes implicados en la formación de biofilm mediante PCR en tiempo real

\begin{tabular}{|c|c|c|c|}
\hline $\begin{array}{l}\text { Primer } \\
\text { Nombre } \\
\text { del gen }\end{array}$ & Secuencia & $\begin{array}{c}\text { Tamaño } \\
\text { del producto } \\
\text { en pb }\end{array}$ & Referencia \\
\hline \multirow{2}{*}{ Oxa-51 } & F: 5' - TAA TGC TTT GAT CGG CCT TG-3' & \multirow{2}{*}{$353 \mathrm{pb}$} & \multirow{2}{*}{ Woodford et al } \\
\hline & R: 5'-TGG ATI' GCA CTT CAT CTT GG-3' & & \\
\hline \multirow{2}{*}{ Bap } & F: 5'-ATG CCT GAG ATA CAA ATT AT-3' & \multirow{2}{*}{$1449 \mathrm{pb}$} & \multirow{2}{*}{$\begin{array}{l}\text { Badmasti el aL } \\
2015\end{array}$} \\
\hline & R: 5'-GTC AAT CGT AAA GGT AAC G-3 & & \\
\hline \multirow{2}{*}{ OmpA } & F: 5'- GTT AAA GGC GAC GTA GAC C-3' & \multirow{2}{*}{$578 \mathrm{pb}$} & \multirow{2}{*}{ Smani et al 2014} \\
\hline & R. 5'- CCA GTG TTA TCT GTG TGA CC-3' & & \\
\hline \multirow{2}{*}{ CsuE } & F: 5'-CAT CTT CTA TTT CGG TCC C-3' & \multirow{2}{*}{$168 \mathrm{pb}$} & \multirow{2}{*}{ Azizi et al. 2016} \\
\hline & R:5'- CGG TCT GAG CAT TGG TAA-3' & & \\
\hline
\end{tabular}


Obteniéndose la densidad óptica de corte (Doc) de acuerdo a la siguiendo la fórmula Doc $=\mathrm{DO}+(3 * \mathrm{DS}) 8,14$.

El protocolo de investigación fue aprobado por el Comité de Ética del HMIGU y Hospital Clínico Viedma.

\section{Resultados}

Todas las cepas estudiadas fueron formadores de biopelículas, moderados $65,2 \%$ y $34,8 \%$ fuertes para el Maternológico German Urquidi, en cuanto al Hospital Viedma se registró 6,5\% (11/168) débiles, 44,6\% (75/168) moderados y $48,8 \%(82 / 168)$ formadores fuertes de biopelículas. Como se observa en la Figura 3.

En cuanto al gen bap ninguna cepa del HMIGUlo presenta, para el hospital Viedma existe presencia en un 31,5\% (53/168), como se observa en la figura 4 . El gen bap no presenta relación con la cantidad de biopelícula formada de acuerdo al análisis estadístico.

El gen csuE es el gen de mayor presencia en el Hospital Viedma 99,4\% (167/168) contrario al Maternológico Infantil $1,34 \%(1 / 23)$. Se ha demostrado que este gen no presenta asociación con la cantidad de biopelícula, pero si se encuentra en todos los aislamientos formadores de biopelículas (Figura 4).

El gen ompA se identificó en el 95,6\% (22/23) para el HMIGU y 69\% (116/168) para el Hospital Viedma, para este centro hospitalario se encontró una asociación significativa entre la cantidad de biopelícula y la presencia de este gen, resultado contrario al Materno Infantil (Figura 4).

De igual manera el análisis estadístico de la resistencia de Imipenem y Meropenem frente a la cantidad de biofilm formado mostró una asociación significativa, formadores fuertes de biofilm influyen en la resistencia a ambos carbapenems (Figura 5).

\section{Discusión}

Este estudio permitió establecer un protocolo para cuantificar biopelículas y relacionarla con la cantidad formada, los genes implicados en su formación y la resistencia a los antibióticos. Se estandarizó la detección de genes bla oxa-51, bap, ompA y csuE por PCR en tiempo real a partir de aislamientos de Acinetobacter baumannii del Hospital Viedma y Materno Infantil Germán Urquidi.

La identificación de A. baumannii por reacción en cadena de la polimerasa (PCR) se basa en la presencia de bla OXA51 como demostró Turton et al 19 que puso a prueba la presencia de este gen frente a otras especies del género Acinetobacter y otras bacterias Gram negativas similares como, Stenotrophomona, Pseudomona, Moraxella y Burkhordelia, obteniendo excelentes resultados.

El alto porcentaje de resistencia a los carbapenémicos para el Maternológico (100\%) y el Hospital Viedma (61\% y 61,3\%) son similares a los obtenidos por Vanegas et $\mathrm{al}^{3}$ que identifica a Sudamérica como el continente con más resistencia frente a Europa $(25,7 \%)$ y Estados Unidos (12,1\%), en Argentina se muestra resistencia de $84.9 \%$, Brasil $71,4 \%$, Chile $50 \%$, Chávez et $\mathrm{a}^{15}$ describió en Colombia resistencias de $96,2 \%$ y $100 \%$ para Meropenem e Imipenem respectivamente, Ciello et $\mathrm{al}^{16}$ en Brasil describió un $66,1 \%$ similar a otros estudios.

En Bolivia el 2008 Fernández et a ${ }^{17}$ determinó resistencia
$39,71 \%$ para carbapenems, similares resultados obtuvieron Sevillano et al 17 en 2008-2009 con 35\% de resistencia al Imipenem, en 2014 Parra et a ${ }^{18}$ describió resistencia de 38\% y 39\% para Imipenem y Meropenem, resultados diferentes a nuestro estudio. Sin embargo, el 2015 Fernández et $\mathrm{al}^{17}$ demostró aumento significante en la resistencia de los carbapenémicos a $95,1 \%$ y se encontró un aislamiento con resistencia a Colistina lo que demostró el comienzo de alta resistencia.

El enfoque principal de este trabajo radica en la biopelícula producida por A. baumannii, se estudió la cantidad y los genes asociados a su formación, resistencia asociada a Imipenem y Meropenem.

Gómez et al 20 el 2012 clasificó la cantidad de biopelícula de varias bacterias Gram negativas, de acuerdo a la técnica descrita por Stephanovic et $\mathrm{al}^{8}$, siendo A. baumannii una bacteria no formadora de biopelícula (60\%), diferente a nuestro estudio donde todas las cepas de A. baumannii son formadores de biopelícula, más del $90 \%$ entre moderados y fuertes.

La asociación de CsuE y la cantidad de biopelícula formada no presentan relación de acuerdo a los resultados de chi cuadrado, este gen está implicado en la formación de pilis. La adherencia del pili a la superficie es el primer paso para la formación de biopelícula y no se relaciona con la cantidad o espesor formado, lo que explica la amplia distribución y que todas las cepas estudiadas sean formadoras de biopelícula sin importar la cantidad, Breij et $\mathrm{al}^{21}$ demostró que su mutación afecta la formación de pilis, produciendo pilis más cortos y delgados afectando la formación de biopelícula.

En A. baumannii el gen OmpA presenta una distribución extensa, Liu et al ${ }^{22}$ el 2013-2014 describió un 100\% de presencia un resultado similar a Badmasti et $\mathrm{al}^{13}$, similares resultados al HMIGU (95\%) y menor cantidad para el Hospital Viedma (69\%).

Ma et a ${ }^{23}$ en 2008 describió el efecto de la delección de ompA en E. coli produciendo la disminución de la cantidad de biopelícula de 10 a 20 veces. El resultado obtenido en el estudio para A. baumannii de manera similar demostró para el Hospital Viedma que existe la asociación de este gen con la cantidad de biopelícula formada.

En cuanto al gen bap identificado por primera vez en Staphylococcus aureus presenta estudios como Cucarella et al ${ }^{24}$ quien describió la importancia de este gen en la formación de biopelícula. Badmasti et al 13 describió una distribución del $30 \%$ del gen bap en cepas de Acinetobacter baumannii, un resultado diferente describió Luo et al 5 84\% del gen bap en A. baumannii.

El estudio de biopelícula en $A$. baumannii es de gran interés por la resistencia a los antibióticos que afrontamos en la actualidad, sin embargo, en la actualidad existen pocos estudios dedicados a la cuantificación de biopelícula en esta bacteria.

Srinivasa et al ${ }^{25}$ demostró la correlación entre la cantidad de biopelícula con la multirresistencia a Imipenem y Meropenem, un resultado similar al que obtuvimos demostrando que cepas formadoras fuertes de biopelícula se asocian con la resistencia a carbapenems en cepas de Acinetobacter baumannii.

\section{Conflicto de intereses}

Los autores declaran no tener ningún conflicto de intereses. 


\section{Referencias bibliográficas}

1. López M., Zerquera J., Iglesias M., Rodríguez Y. Aislamientos de Acinetobacter en pacientes ingresados en Unidades de Cuidados intensivos. 2018:16 (3): 399-409. Disponible en: http://scielo. sld.cu/scielo.php?script=sci_arttext\&pid=S1727 897X2018000300008\&lng=es.

2. Koneman E. Diagnóstico microbiológico. 5th ed. Buenos Aires: Médica Panamericana; 2008.

3. Vanegas J., Roncacio G. y Jimenez J. .A. baumannii: Importancia clínica, mecanismos de resistencia y diagnóstico. Rev CES Med. 2014; 28 (2), 233-246. Disponible en: www.scielo.org.co/ pdf/cesm/v28n2/v28n2a08.pdf

4. García G., Damiani E., Copa H., Ruiz E., Santalla J., Revollo C. Mehlis A., Molina I. y Mamani A. Huellas digitales de cepas de Acinetobacter baumannii procedentes de pacientes hospitalizados en la caja petrolera de salud de Obrajes, mediante el método de Pulsed field gel electrophoresis PFGE, La Paz, Bolivia, marzo 2015. Journal of the Selva andina research society. 2017;8(1). Disponible en: http://www. scielo.org.bo/scielo.php?script=sci_arttext\&pid =S2072-92942017000100006

5. Luo T., Rickard A., Srinivasan U., Kaye K. y Foxman B. Association of blaOXA-23 and bap with the persistence of Acinetobacter baumannii within a major healthcare system. Frontiers in microbiology. 2015; 6(182).

Disponible en: Frontiers | Association of blaOXA-23 and bap with the persistence of Acinetobacter baumannii within a major healthcare system | Microbiology (frontiersin.org) 6. Goh S., Beatson S., Totsika M., Moriel D., Phan M., Szubert J., Runnegar N., Sidjabat H., Paterson D., Nimmo G., Lipman J. y Schembria M. Molecular Analysis of the Acinetobacter baumannii Biofilm-Associated Protein. Applied and Environmental Microbiology. 2013; 79 (21): 6535-43. Disponible en: https://www.ncbi. nlm.nih.gov/pmc/articles/PMC3811493/ DOI: 10.1128/AEM.01402-13

7. Cruz S., Tapia G., Castañón C. Distribución de genes de adhesión y regulación de biofilm en Staphylococcus aureus. 2016;50(4):713-720.

Disponible en:: https://www.redalyc.org/articulo. oa? id $=53550527020$

8. Stepanovic S., Vukovic D., Hola V., Bonaventura G., Djukic S., Cirkovic I. y Ruzicka F. Quantification of biofilm in microtiterplates: overview of testing conditions and practical recommendations for assessment of biofilm production by staphylococci. APMIS. 2007; 115 891-899.

Disponible en: Quantification of biofilm in microtiter plates: overview of testing conditions and practical recommendations for assessment of biofilm production by staphylococci - PubMed (nih.gov)

9. Gaddy J., Tomarasi A., Actis Luis A. La proteína acinetobacter baumannii 19606 OmpA juega un papel en la formación de biopelículas en superficies abióticas y en la interacción de este patógeno con células eucariotas. 2020; 77-8.

https://journals.asm.org/doi/full/10.1128/ IAI.00096-09 - pill-con1

10. Smani Y., Fabregas A., Roca I., Sanchez V., Vila J y Pachon J. Role of OmpA in the Multidrug Resistance Phenotype of Acinetobacter baumannii. Antimicrobial Agents and Chemotherapy. 2014:58 (3): 1806-1808. Disponible en: Role of OmpA in the multidrug resistance phenotype of Acinetobacter baumannii - PubMed (nih.gov)

11. Turton J, Woodford N, Glover J, Yarde S, Kaufmann M, Pitt T. Identification of Acinetobacter baumannii by Detection of the bla OXA-51-like Carbapenemase Gene Intrinsic to This Species. Journal of Clinical Microbiology. 2006;44(8):2974-2976. Disponible en: https://doi. org/10.1099/mic.0.27865-0

12. Brossard K, Campagnari A. The Acinetobacter baumannii Biofilm-Associated Protein Plays a Role in Adherence to Human Epithelial Cells. Infection and Immunity. 2011;80(1):228-233. Disponible en: The Acinetobacter baumannii biofilm-associated protein plays a role in adherence to human epithelial cells - PubMed (nih.gov) DOI: 10.1128/IAI.05913-11

13. Badmasti F, Siadat S, Bouzari S, Ajdary S, Shahcheraghi F. Molecular detection of genes related to biofilm formation in multidrugresistant Acinetobacter baumannii isolated from clinical settings. Journal of Medical Microbiology. 2015;64(5):559-564. Disponible en: Molecular detection of genes related to biofilm formation in multidrug-resistant Acinetobacter baumannii isolated from clinical settings - PubMed (nih.gov) DOI: $10.1099 / \mathrm{jmm} \cdot 0.000058$

14. Azizi O., Shahcheraghi F., Salimizand H., Modarresi F., Shakibaie M., Mansouri S., Ramazanzadeh R., Badmasti F. y Nikbin V. Molecular Analysis and Expression of bap Gene in Biofilm-Forming Multi-Drug-Resistant Acinetobacter baumannii. Reports of biochemistry and molecular biology. 2016: 5 (1): 62-72. Disponible en: https://www.scirp.org/reference/ ReferencesPapers.aspx?ReferenceID $=2288781$

15. Chávez M., Gómez R., Cabrera C. y Esparza M. Patrones de resistencia a antibióticos de Acinetobacter baumannii en un hospital de Colombia. An Fac Med. 2015; 76 (1): 21-26. Disponible en:

ht t p s: / / w w w. researchgate.net / publication/276211832_Patrones_de_ resistencia_a_antibioticos_de_Acinetobacter baumannii_en_un_hospital_de_Colombia

16. Ciello G. y Costa M. . Perfil epidemiológico del Acinetobacter baumannii resistente al carbapenem en un hospital en el interior del estado de Minas Gerais. REFACS. 2016; 4 (3): 201-207. Disponible en: http://seer.uftm.edu.br/revistaeletronica/ index.php/refacs/article/download/1772/1723

17. Sevillano E., Fernandez E., Bustamante Z.,
Zabalaga S., Rosales I., Umaran A. y Gallego L. Emergence and clonal dissemination of carbapenem-hydrolysing OXA-58-producing Acinetobacter baumannii isolates in Bolivia. Journal of medical microbiology. 2012; 61: 8084. Disponible en: https://www.ncbi.nlm.nih.gov/ pubmed/21873380

18. Parra D. y Rada J. Perfil de Sensibilidad y Resistencia Antimicrobiana de Acinetobacter spp. en el Hospital Municipal Boliviano Holandés. Rev Soc Bol Ped. 2016; 55(1): 3-10. Disponible en: http://www.scielo.org.bo/scielo.php?script=sci_ar ttext\&pid=S1024-06752016000100002

19. Turton J, Woodford N, Glover J, Yarde S, Kaufmann M, Pitt T. Identification of Acinetobacter baumannii by Detection of the bla OXA-51-like Carbapenemase Gene Intrinsic to This Species. Journal of Clinical Microbiology 2006;44(8):2974-2976. Disponible en: https:// jcm.asm.org/content/44/8/2974 DOI: https://doi. org/10.1128/JCM.01021-06

20. Gómez J., Gómez M., Bas P., Ramos C., Cafini F., Maestre J. y Prieto J. ¿Es la cuantificación del biofilm un elemento diferenciador en la patogenia de bacilos gramnegativos?. Rev Esp Quimioter. 2013;26(2):97-102. Disponible en: https://dialnet. unirioja.es/servlet/articulo? codigo $=6303257$

21. Breij A., Gaddy J., Meer J., Koning R., Koster A., Broek P., Actis L., Nibbering P. y Dijkshoorn L. . Research in Microbiology. 2009; 160: 213-218 Disponible en:

https://www.ncbi.nlm.nih.gov/pubmed/19530313 22. Liu H., Wu Y., Chen L., Gao X., Huang H., Qiu F. y Wu D. Biofilm-Related Genes: Analyses in MultiAntibiotic Resistant Acinetobacter Baumannii Isolates From Mainland China. Med Sci Monit. 2016; 22: 1801-1807. Disponible en:

http://europepmc.org/articles/PMC4913728

23. Ma Q. y Wood T. OmpA influences Escherichia coli biofilm formation by repressing cellulose production through the CpxRA two-component system. Environmental Microbiology. 2009; 11(10): 2735-2746. Disponible en:

\section{http://europepmc.org/articles/PMC4913728}

24. Cucarella C., Solano C., Valle J., Amorena B., Lasa I. y Penades J. Bap, a Staphylococcus aureus Surface Protein Involved in Biofilm Formation. Journal of bateriology. 2001; 183 (9): 2888-2896. Disponible en: https://jb.asm.org/ content/183/9/2888

25. Rao, R.S., Karthika, R.U.,Singh, S.P.,Shashikala, P., Kanungo, R., Jayachandran, S., \& Prashanth, K. Correlation between biofilm production and multiple drug resistance in imipenem resistant clinical isolates of Acinetobacter baumannii. Indian journal of medical microbiology, 2008; 26(4): 333-337. Disponible en: https://pubmed. ncbi.nlm.nih.gov/18974485/ DOI: https://doi org/10.4103/0255-0857.43566 